\title{
«CONSTITUCIONALISMO»: PROBLEMAS DE DEFINICIÓN Y TIPOLOGÍA*
}

\author{
Paolo Comanducci \\ Universidad de Génova
}

\begin{abstract}
RESUMEN. El autor analiza y critica la definición de «constitucionalismo» de FERRAJOLI y su tipología de los constitucionalismos. Él afirma la oportunidad de distinguir entre constitucionalismo como teoría, como metodología y como ideología.
\end{abstract}

Palabras clave: constitucionalismo, definición, tipología, FerRAJOLI.

ABSTRACT. The author analyses and criticises the FERRAJOLI's definition of "constitutionalism" and his typology of constitutionalisms. He maintains the opportunity of distinguishing among constitutionalism as a theory, as a methodology and as an ideology.

Keywords: constitutionalism, definition, typology, FERRAJOLI.

* Fecha de recepción: 10 de enero de 2011. Fecha de aceptación: 7 de febrero de 2011. 


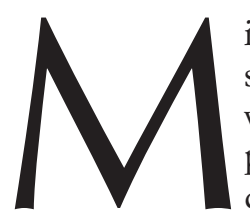
i discusión de algunas tesis expresadas por Luigi FERRAJOLI en el ensayo Constitucionalismo principialista y constitucionalismo garantista va a ser aburrida y probablemente de escaso interés para los demás, pero, justamente para evitar que sea aburridísima, he tratado al menos que sea muy breve. Voy a concentrarme sólo sobre algunas cuestiones de definición y clasificación del constitucionalismo, ya que comparto muchas de las cosas que FERRAJOLI escribe en su ensayo contra el «constitucionalismo argumentativo o principialista» y no quiero, por otro lado, volver a insistir sobre viejos temas de mi debate con FERRAJOLI.

FERRAJOLI propone una revisión terminológica respecto al uso de «(neo)constitucionalismo» que se ha ido afirmando en la última década en Italia y en los países de habla hispana. Pero antes de la re-definición nos brinda un pequeño panorama de los usos corrientes de la palabra «constitucionalismo».

Según su reconstrucción, hay dos diferentes acepciones de «constitucionalismo»: una política y una jurídica. La acepción política designa, en la antigüedad como en la Edad moderna, una «práctica y concepción de los poderes públicos dirigidas a su limitación, en garantía de determinados ámbitos de libertad». La acepción jurídica designa en cambio un tipo de sistema jurídico, mejor dicho un tipo de modelo institucional, que el mismo FERRAJOLI generalmente llama Estado constitucional de Derecho, y, al mismo tiempo, una teoría del Derecho. Esta última tiene por objeto aquel modelo institucional, y se caracteriza por una concepción de la validez de las leyes como dependiente no sólo de requisitos procedimentales sino más bien sustanciales, es decir, de la conformidad de los contenidos de las leyes al contenido de la constitución. El constitucionalismo en su acepción jurídica abarcaría dos diferentes concepciones: una de corte iusnaturalista y otra de corte iuspositivista. La primera se opone al positivismo jurídico, la segunda quiere complementarlo. El constitucionalismo iusnaturalista, en la reconstrucción de FERRAJOLI, sería el que hoy muchos autores llaman neoconstitucionalismo. El positivismo jurídico, a la par del constitucionalismo, designaría no sólo una teoría sino un modelo institucional, el así llamado Estado legislativo de Derecho.

Después de haber criticado como «equívoca y engañosa» la terminología corriente, FERRAJOLI avanza una re-definición de «constitucionalismo» y una correlativa tipología de los constitucionalismos contemporáneos. Sugiere emplear únicamente la noción jurídica - pero sin indicar cómo deberíamos llamar al constitucionalismo políticoPropone hablar de «"ius-constitucionalismo" o "constitucionalismo jurídico", o mejor aún "Estado constitucional de Derecho" o simplemente "constitucionalismo"» para designar el modelo institucional caracterizado por la superioridad de la constitución sobre la ley y por el control de constitucionalidad, y también —es lícito inferir- las concepciones filosóficas y metodológicas que tienen por objeto este modelo. Sucesivamente FERRAJOLI presenta su tipología de los constitucionalismos que acaba de definir, distinguiendo entre constitucionalismos iusnaturalistas e iuspositivistas; dentro de los iusnaturalistas, hace hincapié en la variante contemporánea, que apoda «constitucionalismo argumentativo o principialista», mientras que, dentro de los iuspositivistas, recalca el «constitucionalismo normativo o garantista». De ambos ofrece, en su ensayo, una caracterización y un análisis comparativo, para finalmente criticar el primero y defender el segundo con abundancia de argumentos. 
A continuación voy a presentar cuatro observaciones críticas sobre la propuesta de FERRAJOLI.

1. La primera es acerca de su re-definición. Sería, a mi parecer, más claro caracterizar por separado el objeto normativo e institucional, es decir, los modelos de Estado constitucional y de Estado legislativo, respectivamente, y no llamar del mismo modo las teorías que versan sobre ellos o las doctrinas normativas o axiológicas relativas a tales modelos. En efecto, no todo lo que se puede afirmar acerca del constitucionalismo o del positivismo como modelos institucionales se puede igualmente afirmar acerca de las teorías o de las doctrinas, y viceversa. Por ejemplo, parece evidente que no tiene ningún sentido hablar de constitucionalismo iusnaturalista o iuspositivista, principialista o garantista si con «constitucionalismo» se designara un modelo institucional. Además es preciso observar que hay independencia y no conexión necesaria entre el nivel de las ideas y el nivel de las instituciones: bien podría haber teorías, enfoques o ideologías constitucionalistas que tengan — tal vez críticamente- por objeto modelos positivistas, o, al revés, bien podría haber teorías, enfoques o ideologías positivistas que tengan por objeto modelos constitucionalistas. Si es así, resulta manifiestamente equívoco hablar de «constitucionalismo» o de «positivismo» para hacer referencia conjuntamente a teorías (y doctrinas) y a modelos.

2. La re-definición de FERRAJOLI presenta además un inconveniente menor: si «constitucionalismo» se usara sólo para designar el constitucionalismo jurídico, habría que llamar de otra forma al constitucionalismo político. Por tanto resultaría quizá mejor usar la palabra «iusconstitucionalismo» para distinguir esta idea frente al constitucionalismo político. Pero, si se aceptara la observación sub 1, es decir, si se usa «iusconstitucionalismo» para designar sólo teorías (y doctrinas) y no un modelo institucional, ¿cuál sería la diferencia entre usar «iusconstitucionalismo» y usar «neoconstitucionalismo»? En mi opinión, prácticamente ninguna que tenga trascendencia. En ambos casos el elemento común que permite usar aquellos rótulos para designar estas teorías o doctrinas está constituido por la centralidad asignada a su objeto, es decir, al modelo institucional denominado Estado constitucional de Derecho. Es el objeto que justifica el uso de «ius- o neoconstitucionalismo» para designar teorías o doctrinas que, por otro lado, difieren mucho entre sí.

FERRAJOLI en contra del uso de «neoconstitucionalismo» presenta, entre otros, el argumento según el cual esta palabra sugiere la idea de una estrecha vinculación entre el «nuevo» constitucionalismo y el «antiguo», es decir, el constitucionalismo político. Esta vinculación debe ser rechazada, en su opinión, porque, en un sentido, el constitucionalismo político sería un conjunto de garantías de la libertad externas al sistema jurídico mientras que el (ius- o) neoconstitucionalismo es un sistema de garantías internas, y, en otro sentido, el constitucionalismo político es una ideología política, de corte liberal, mientras que el (ius- o) neoconstitucionalismo es una teoría del Derecho. El argumento obviamente presupone una de las tesis centrales de la postura teórica de FERRAJOLI, según la cual el Estado constitucional de Derecho, con la introducción de la rigidez de la constitución, constituye un «cambio de paradigma [...] en la estructura del Derecho positivo». Si se negara esta premisa — por ejemplo insistiendo sobre la existencia de garantías jurídicas internas también en el Estado legislativo-, el argumento perdería casi por completo su fuerza. Además no sería difícil encontrar razones 
a favor del uso del prefijo «neo», es decir, a favor de la opción de destacar los nexos de continuidad entre constitucionalismo político y jurídico, sin olvidar, por supuesto, sus diferencias. Por ejemplo, una de las características más evidentes que el neoconstitucionalismo contemporáneo comparte con el constitucionalismo político es la idea del Derecho como límite del poder: los dos tipos de constitucionalismos la declinan en modo diferente, pero se trata de un rasgo distintivo común, de corte liberal y antimayoritario. En conclusión, bien que se elija uno u otro prefijo, «neo» o «ius», igualmente se transmite la idea de que hay continuidad pero también diferencias entre los dos tipos de constitucionalismo: elegir al primero subraya más la continuidad, elegir al segundo subraya más las diferencias. No me parece que haya muchas razones para continuar esta discusión, que resulta ser poco más que una cuestión de matices.

3. Sigue siendo oportuno, en mi opinión, emplear la vieja distinción de BobBiO entre positivismo como teoría, como metodología y como ideología, y no discutir nunca a favor o en contra del iuspositivismo a secas, sin previamente aclarar a qué tipo de positivismo se está haciendo referencia. Se trata en efecto de posturas diferentes y no necesariamente conectadas entre sí, de modo que alguien puede definirse positivista en una acepción de «positivismo» y no-positivista o incluso anti-positivista en otra acepción del término.

De la misma forma, sigue pareciéndome oportuno distinguir entre (ius- o) neoconstitucionalismo como teoría, como metodología y como ideología, y no discutir nunca a favor o en contra del neoconstitucionalismo a secas, sin previamente aclarar a qué tipo de neoconstitucionalismo se está haciendo referencia. En este caso también se trata de posturas diferentes y no necesariamente conectadas entre sí, de modo que alguien puede ser neoconstitucionalista en una acepción de «neoconstitucionalismo» y no serlo en otra. Como es el caso del mismo FERRAJOLI.

Ya aclaré que estoy de acuerdo con FERRAJOLI en opinar que el elemento común a todos los (ius- o) neoconstitucionalismos es la centralidad asignada al objeto de la teoría (y de la ideología): el modelo de Estado constitucional de Derecho y a sus realizaciones efectivas en los países contemporáneos. Lo que no comparto con él, y con la gran mayoría de los neoconstitucionalistas, es la idea de que, para dar cuenta de este objeto, haga falta necesariamente una teoría jurídica normativa. Y sobre esto volveré rápidamente al final de mi contribución. Es preciso sin embargo destacar que quizás haya una razón que explica la «incomodidad» que FERRAJOLI siente al ser etiquetado como neoconstitucionalista, mientras que acepta sin problemas el rótulo de iusconstitucionalista. En la tipología del positivismo jurídico presentada por BoBBIO hay una suerte de primacía conceptual del positivismo metodológico sobre los demás: la definición misma del iuspositivismo - en BOBBio más aún que en HART y sus discípulos- depende de la distinción entre el Derecho como es y como debería ser, es decir, del positivismo metodológico, que constituye el presupuesto de la teoría y de la ideología positivistas. $\mathrm{Si}$, de forma análoga, se asumiera que existe una primacía conceptual del neoconstitucionalismo metodológico sobre los demás y que la definición misma del neoconstitucionalismo depende de la conexión necesaria — por medio de los principios, valores y derechos fundamentales contenidos en las constituciones - entre Derecho y moral, entonces una postura como la de FERRAJOLI no podría ser etiquetada como neoconstitucionalista. De aquí, creo, viene la incomodidad a la que hacía referencia. Pero si se 
asume, como estoy haciendo en estas páginas y de acuerdo con la propuesta de FERRAJOLI, que el elemento definitorio del (ius- o) neoconstitucionalismo está formado por el relieve atribuido a su objeto, es decir, al Estado constitucional de Derecho, entonces la incomodidad debería desaparecer.

4. La tipología de FERRAJOLI, lejos de ser «falsa» —ya que ninguna tipología lo es, por su naturaleza-, me parece sin embargo menos útil de la que presenté en algunos trabajos de la última década ${ }^{1}$, justamente porque no distingue con claridad entre (ius- o) neoconstitucionalismo como teoría, como metodología y como ideología, y porque divide los neoconstitucionalistas en dos grupos: por un lado FERRAJOLI, ipor el otro todos los demás! Estoy visiblemente exagerando, pero no tanto. Luigi afirma que mi tipología «ignora» el iusconstitucionalismo garantista: no es verdad —las tesis de FERRAJOLI concurren en conformar la teoría neoconstitucionalista-, pero sí es verdad que mi tipología no asigna al iusconstitucionalismo garantista un rol ni protagónico ni categorial. FERRAJOLI elige como elemento de distinción entre los dos tipos de iusconstitucionalismos - el principialista y el garantista, respectivamente- el ser o no ser iusnaturalista, o cuanto menos el ser o no objetivista moral. Yo diría en cambio que esto distingue a los autores sólo en el nivel de la metodología, y tampoco necesariamente. Únicamente quien niega la gran división entre ser y deber ser tiene necesariamente que rechazar el positivismo metodológico: hay iusnaturalistas (o cuanto menos objetivistas morales) que, como Carlos NINO, se adhieren al positivismo metodológico sin contradecirse. No obstante, como cuestión de hecho y contingente es verdad que hoy en día la mayoría de los neoconstitucionalistas son objetivistas y adversarios del positivismo metodológico.

Por otro lado, varias posturas de FERRAJOLI lo acercan, en mi opinión, al iusconstitucionalismo principialista mucho más de lo que él estaría quizá dispuesto a reconocer. En primer lugar, el constitucionalismo garantista, en tanto que filosofía y teoría política, comparte de manera explícita con el principialista un claro apoyo al modelo ideal del Estado constitucional de Derecho, y a los principios, valores y derechos fundamentales que lo caracterizan. En segundo lugar, el constitucionalismo garantista comparte el afán de muchos constitucionalistas principialistas por un cambio de paradigma de la teoría del Derecho, que debería hoy en día caracterizarse como normativa. Es, sin embargo, evidente que las razones de este cambio no son las mismas para FERRAJOLI que para los partidarios del constitucionalismo principialista.

Dejando de lado estos últimos, las razones de FERRAJOLI radican, como se sabe, en el cambio paradigmático del objeto mismo de la teoría: el Derecho constitucionalizado sería un objeto que requiere una teoría normativa. Pero, ¿por qué el cambio de sistema jurídico debería afectar a la teoría? La única explicación sensata que se me ocurre hace hincapié en la proximidad de FERRAJOLI con el constitucionalismo principialista. En efecto, los distintos niveles normativos — que constituirían en su opinión la diferencia entre Estado constitucional y Estado legislativo- existían también en el Estado legislativo de Derecho: piénsese por ejemplo en los niveles de la ley y del reglamento, o de la ley y de la sentencia. Allí también la validez de un reglamento o de una sentencia

1 Cfr. ahora P. Comanducci, Hacia una teoría analítica del Derecho. Ensayos escogidos, R. EsCUDERO Alday (ed.), Madrid, Centro de Estudios Políticos y Constitucionales, 2010, 251-264. 
dependía no sólo de cuestiones procedimentales, sino de su conformidad a la ley. También en el Estado legislativo la validez era cuestión de contenido y no sólo de forma. Parecería por tanto que lo que FERRAJOLI quiere subrayar — hablando de «cambio de paradigma»- es que en el nivel constitucional hay unos especificos contenidos (los principios, valores y derechos fundamentales) que no estaban previstos o garantizados en el Estado legislativo. La teoría del Derecho encontraría entonces la justificación de su normatividad en la necesidad de implementar estos contenidos en los niveles jurídicos infra-constitucionales. Si así es, las diferencias entre el constitucionalismo garantista de FERRAJOLI y el constitucionalismo principialista se difuminan, ya que la normatividad de la teoría garantista sería más bien de corte político-moral que metodológico.

Para evitar esta conclusión, creo que FERRAJOLI debería abandonar su uso a veces ambiguo de «ciencia jurídica» y distinguir claramente entre dogmática y teoría del Derecho. La primera siempre es —y según FERRAJOLI debe ser, al menos en el Estado constitucional de Derecho- normativa. La segunda, en cambio, debe guardar su carácter a-valorativo, o como máximo ser normativa sólo desde un punto de vista metodológico. 